Special Issue of the 8th International Advances in Applied Physics and Materials Science Congress (APMAS 2018)

\title{
The Application of Transmission Electron Microscopy to the Analysis of Powder Coatings Deposited on Metal Substrates by Plasma Method
}

\author{
D. Alontseva ${ }^{a, *}$, E. Ghassemieh ${ }^{b}$ And A. Dzhes ${ }^{c}$ \\ ${ }^{a}$ D. Serikbayev East Kazakhstan State Technical University, Department of Instrument Engineering \\ and Technology Process Automation, 070004, Ust-Kamenogorsk, Kazakhstan \\ ${ }^{b}$ University of Sunderland, Faculty of Engineering and Advanced Manufacturing, SR6 0AN, Sunderland, UK \\ ${ }^{c}$ D. Serikbayev East Kazakhstan State Technical University, Department for Research \\ and Development and Innovative Activity, 070004, Ust-Kamenogorsk, Kazakhstan
}

\begin{abstract}
This paper presents the experimental techniques of transmission electron microscopy of plasma-spray powder alloy coatings. It includes the specimen preparation techniques for powder materials and for plasma spray powder coatings from the nickel-chromium-based alloy and synthetic hydroxyapatite (HA) and the analysis of the results. The study of the structure-phase compositions of HA powders and HA and Ni-Cr-based plasma spray coatings has been carried out by using transmission electron microscopy on JEM-2100 (JEOL), and by X-ray diffraction (XRD) on X'Pert PRO diffractometer (PANalytical, the Netherlands). It has been established that the coatings have the desired structure-phase composition as a result of the selection of specific modes of plasma spraying and additional plasma treatment. The advantages and challenges of application of TEM method for analyzing the structure of thick (up to $300 \mu \mathrm{m}$ ) powder coatings deposited by plasma spraying methods onto metal substrates are investigated.
\end{abstract}

DOI: 10.12693/APhysPolA.135.1113

PACS/topics: TEM, XRD, specimen preparation, plasma spray powder coatings, hydroxyapatite (HA)

\section{Introduction}

Thermal coating spraying has attracted increased interest worldwide due to multiple advantages such as high productivity of the process, good adhesion of the coating to the substrate, and the ability to apply coatings of refractory materials. Thermal spraying is a relatively "cold" process, and the substrate is usually not heated above $100^{\circ} \mathrm{C}$, which ensures its minimal thermal degradation. This is one of the advantages of the thermal spraying process. Thus, thermal coating spraying finds application in various industries for deposition of wearresistant, a corrosion resistant and heat-resistant, bioceramic, decorative and other types of coatings $[1,2]$. The main purpose of thermal sprayed coatings is normally protection of surfaces of parts operating under conditions of increased friction, temperatures and aggressive environments: cylinder liners, shafts, etc. The method of microplasma spraying of hydroxyapatite powders onto metals surfaces of implants is generally to enhance biocompatibility and bioactivity of the medical implants $[3,4]$. In application of powder plasma coating, controlling the microstructural parameters of the coating, such as the desired structural-phase composition, the required porosity and morphology are of significance. In many cases, the study of the structure of coatings, for example, their

*corresponding author; e-mail: dalontseva@mail.ru porosity is carried out using scanning microscopy $[5,6]$. One of the main methods of analysis of the structuralphase composition of coatings, is using the X-ray diffraction $[7,8]$. The methods of transmission electron microscopy (TEM) is used less often for research of plasma spray powder coatings, despite the fact that it provides the opportunity of observation of dislocations and the morphology of nanoparticles [9-11]. The analytical transmission electron microscopy can be used to endorse the structural characteristic correlation to microhardness and electrochemical behavior of coatings [12-14]. The main advantage of using TEM technique/equipment is a possibility to get high resolution images on a nanometer scale. However the difficulties of preparing suitable samples of the porous and relatively thick plasma spray coatings for the TEM study lead to the fact that these coatings are rarely investigated using the TEM method.

Currently, varieties of techniques for preparing samples for TEM study exist. These techniques are actively being developed, giving researchers the opportunities to select suitable methods depending on their objectives [15]. However, there are some limitations in application of TEM in analysis of plasma spray powder coatings. These include long specimen preparation time in general and the difficulty of preparing specimens in particular. The structure of thermal spray coatings is normally very heterogeneous. This is due to the formation of a plasma spray coating being a chaotic process [1]: molten particles spread out and deform as they strike a substrate, 
voids occur, particles overheated in the spray jet become oxidized and unmelted particles are embedded in the coating. The specimens of plasma spray coatings for TEM research are difficult to prepare, especially the specimens of porous coatings, because they easily break down (crumble) during preparation. Before starting the TEM study, it is crucial to identify the objectives of the study and the expected findings.

The purpose of this research study is to investigate the advantages and challenges of application of TEM method for analyzing the structure of thick (up to $300 \mu \mathrm{m}$ ) hydroxyapatite (HA) powder coatings deposited by plasma spraying methods onto metal implant substrates.

It is the objective of our research to establish the morphology of the hardening intermetallic phase in the NiCr-based powder coatings using TEM. We examine the suggestion that an increase in the volume fraction of this hardening phase can be achieved with an additional coating treatment. This additional coating involves application of plasma jet ensuring the formation of relatively low temperatures in these coatings (about $400^{\circ} \mathrm{C}$ at the coating boundary with the substrate). In our previous publications we have explained $[12,14]$ the choice of the appropriate additional treatment modes and the expected cellular precipitation of the strengthening phase lamellas from the solid solution of the coating matrix. We also indicated a possible formation of nanoscale structure formation in the coating using TEM images. Here we focus on the description of methods for preparing samples of initial powder and the final plasma coatings. We then present the results of our TEM study.

It is also important to apply our proven techniques of TEM specimen preparation for porous HA plasma spray powder coatings. This is essential for comparing the results of analysis of the structural-phase compositions of the initial hydroxyapatite powders and the resulted coatings. In fact, some of the phases of HA coating such as $\beta$ phase of tricalcium phosphate (TCP) and amorphous HA (resulted from plasma spraying) dissolve in the environment of a living organism. Therefore they largely affect the potential fixation of the HA coated implants and their subsequent behavior. Therefore, to define the potential performance of the hydroxyapatite coated implants, we have examined the volume fraction of $\beta$-TCP and amorphous phase in the coatings. Moreover the method of specimen preparation for TEM investigation of the samples before and after the coating process is presented.

\section{Materials and equipments}

Microplasma spraying of the powders and the additional treatment of plasma spray powder coatings by plasma jet have been carried out by microplasmatron MP-004 (developed by the specialists of the E.O. Paton Institute of Electric Welding (IES) (Kiev, Ukraine) [16]. The microplasmatron has been mounted on an industrial robot arm (Kawasaki RS-010LA, Kawasaki Robotics, Japan). It is able to move horizontally along a computed trajectory at designed speed. The thickness of the coatings has been varied from 100 to $300 \mu \mathrm{m}$ by changing the modes of microplasma spraying. The additional treatment of the samples by a plasma jet is carried out at power density of $2.0 \times 10^{9} \mathrm{~W} / \mathrm{m}^{2}$ with $0.006 \mathrm{~m} / \mathrm{s}$ of the plasma jet travel speed. A two stage coating process has been implemented. The first stage is application of $\mathrm{Ni}-\mathrm{Cr}$ -based protective coatings on steel substrates, the PG$19 \mathrm{~N}-01$ powder of standard composition [17]: Ni-based powder alloy with addition of $\mathrm{Cr}(14 \ldots 20 \%)$, B (3.5\%), Si $(4.3 \%), \mathrm{Fe}(7 \%), \mathrm{C}(0.8 \%)$ with average diameter of powders particles is $40-45 \mu \mathrm{m}$.

The PG-19N-01 powder alloys are used for reinforcement and repair of metal components. The modes of microplasma spraying have been as follows: a laminar DC plasma jet; the Ar plasma forming and protective gas; $(1 \ldots 8) \mathrm{mm}$ the diameter of the spray spot; $2 \mathrm{~W}$ the power of plasma source; $2 \mathrm{~kg}$ /hour the powder flow rate; $0.008 \mathrm{~m} / \mathrm{s}$ the plasmatron travel speed. The additional treatment of the plasma spray coatings by a plasma jet has been carried out at power density of $2.0 \times 10^{9} \mathrm{~W} / \mathrm{m}^{2}$ with $0.006 \mathrm{~m} / \mathrm{s}$ of the plasma jet travel speed. The second stage of coating process involves microplasma spraying of hydroxyapatite (HA) as a biocompatible and bioactive phase. $\mathrm{HA}$ is the calcium phosphate mineral $\mathrm{Ca}_{10}\left(\mathrm{PO}_{4}\right)_{6}(\mathrm{OH})_{2}$ of apatite group. In medical implantology, synthetic hydroxyapatite is used as implants coating, promoting new bone formation. HA powder of a fission-fragment shape with a large sizes difference across the particle axes has been used for microplasma spraying. The powder has been represented by a fraction of $50 \ldots 80 \mu \mathrm{m}$, characterized by a tapped density of $1.07 \mathrm{~g} / \mathrm{cm} 3$ and particles density of $2.995 \mathrm{~g} / \mathrm{cm}^{3}$. The phase composition of the powder is an all-crystalline combination of $\mathrm{Ca}_{10}\left(\mathrm{PO}_{4}\right)_{6}(\mathrm{OH})_{2}$ with a molar ratio $\mathrm{Ca} / \mathrm{P}$ 1.67. Grade 5 ELI titanium alloy samples were used as substrates for HA-powders microplasma spraying. The parameters of the microplasma spraying of the hydroxyapatite powders are presented in Table I.

TABLE I

HA powders microplasma spraying parameters.

\begin{tabular}{c|c}
\hline \hline Parameter & Setting \\
\hline primary gas & argon \\
powder carrier gas & argon \\
traverse velocity $[\mathrm{mm} / \mathrm{s}]$ & 50 \\
current $[\mathrm{A}]$ & 45 \\
gas flow rate $[\mathrm{L} / \mathrm{h}]$ & 60 \\
powder feed rate $[\mathrm{g} / \mathrm{min}]$ & 0.4 \\
spray distance $[\mathrm{mm}]$ & 160 \\
carrier gas flow rate $[\mathrm{L} / \mathrm{h}]$ & 240
\end{tabular}

The study of the structure-phase compositions of powders and plasma spray coatings has been carried out by transmission electron microscopy (TEM) on JEM-2100 (JEOL), and X-ray diffraction (XRD) analysis with the use of the X'Pert PRO diffractometer (PANalytical, the Netherlands). The method of arbitrary secant lines was 
used to determine the volume ratio of phases by TEM images. Moreover the Crystal Maker software was used to determine the parameters of the crystal lattice in accordance with TEM micro electromyograms. Five samples of each type were subjected to TEM study. At least 10 TEM images for each type of samples with the minimum of 15 of arbitrary secant lines in were analyzed. An average of 5 diffraction patterns were used to calculate the parameters of every crystal lattice. The structuralphase composition data obtained using TEM were compared with the data obtained using XRD. Interpretation of the X-ray diffraction patterns to measure the crystallinity of the powder HA coatings was carried out using Rietveld method and licensed data of the PCF DFWIN (140,000 connections), the ASTM card file and Diffracts Plus software. The \% crystallinity of the HA powder was calculated using the area of crystalline peaks in the region 20 to $40^{\circ}$ for $2 \theta$ and the area of the amorphous diffuse background in this region. Based on the research objectives, it was necessary to compare the structurephase compositions of the initial powders and plasma spray protective $\mathrm{Ni}-\mathrm{Cr}$ based coatings before and after their additional modification by a plasma jet. To prepare specimens of Ni-Cr based alloys powders for the TEM study, a standard procedure has been chosen. According to this procedure, to observe powders using TEM, the powder particles must be diluted with solvent (by sonication and mixing) before fogging them onto the TEM grid. Ethanol has been used as a solvent for the Ni-Cr based powders. The two main advantages of the ethanol in this case are that it does not react with the metal and also it dries faster than other solvents. Ni-Cr based alloys powders were placed in laboratory glass with ethanol and dispersed in an ultrasonic bath for $1 \mathrm{~min}$. Immediately after this, a drop was taken with a pipette and dropped on the standard TEM grid with a deposited carbon substrate. To prepare the HA powder for the TEM study; we used the same procedure as for $\mathrm{Ni}-\mathrm{Cr}$ based alloys powders.

Samples of plasma coatings for the TEM study have been prepared as follows: thin layers, with a surface deposition of a thickness of $0.5-1 \mathrm{~mm}$, were cut from the original $3 \mathrm{~mm}$ thick plates with a deposited coating thickness of $250 \mu \mathrm{m}$ on a high-precision cutting machine Minitom (Struers, Denmark). The resulting thin plates were cut into squares with a side of $3-4 \mathrm{~mm}$ and rounded to form discs of $3 \mathrm{~mm}$ in diameter. The discs were fixed on a slide using wax with a low melting point. Further, these discs were mechanically thinned on a LaboPol-5 grinding and polishing machine (Struers, Denmark). After this step, it is recommended to use dimple grinding to form a thin region in the center of the sample, for example by Dimple Grinder (Gatan, USA). Then, the thin discs were mounted on the DuoPost 5 (Gatan, USA) holder using a wax with a low melting point and the final thinning of the discs has been carried out until holes formed in the center. For this purpose, the Precision Ion Polishing System PIPS 691 (Gatan, USA) was used. Polishing was carried out in the following modes: the energy of ion guns $-5 \mathrm{kV}$, both guns included, angles $-4 \mathrm{deg}$, rotation of the sample $-3 \mathrm{rpm}$. The time of thinning is 3-4 hours. After that, the disks were washed in acetone, dried and examined by TEM.

\section{Results and discussion}

According to the results of TEM study of nickelchromium alloy powders, the powder does not contain the strengthening $\mathrm{CrNi}_{3}$ phase. This is in agreement with the results of XRD analysis reported in our previous paper [13]. Figure 1 shows the TEM images of the plasma spray coating structure before its additional treatment by microplasma jet. Fig. 1b shows that the $\mathrm{CrNi}_{3}$ phase is released in the form of nanoscale lamellae from the fcc coating matrix $(\gamma$-phase, solid solution on Ni-base with parameter $a=3.5(8) \AA$ ) This consists of crystallographically disoriented, approximately equiaxed grains with a diameter of about $50 \mathrm{~nm}$ (Fig. 1a).

Figure 2 shows TEM images of the same coating after additional plasma jet treatment: the area with $\mathrm{CrNi}_{3}$ lamellae and the corresponding indexed microdiffraction pattern. It has been established by TEM and XRD that the nanograin structure in the coating is retained, and its content in the coating remains unchanged, namely 80 vol\%. Moreover it shows that the strengthening $\mathrm{CrNi}_{3}$ phase (chromium nickel, cubic, Fm-3m, 225 with estimated crystal lattice parameter $3.6 \AA$ ) is precipitated in the coating during the process of microplasma treatment. TEM and XRD methods confirmed a $4 \%$ increase in the volume fraction of $\mathrm{CrNi}_{3}$ phase in the coating after additional microplasma processing (from $5 \mathrm{vol} \%$ to $9 \mathrm{vol} \%$ ). It was established in our previous study that the microhardness of the coatings after additional microplasma treatment is 1.25 times higher than that of the same coatings before irradiation [13]. Thus, the structures observed in the coating before and after additional irradiation are similar (Figs. 1 and 2), however, a slight increase in the volume fraction of the nano-sized $\mathrm{CrNi}_{3}$ phase leads to a hardening of the coating.

It should be noted that the methods of specimen preparation have been sample specific. The development of a suitable technique to suit the plasma spray coatings has been quite challenging and time consuming. It would be desirable to use the cross-section method of specimen preparation. Especially this method would allow studying the structure of different layers of thick coatings [18]. It consists of cutting and gluing (by electron beam stable glue) of material cross section layers and thinning to the state of the TEM sample. The distribution of the temperature field in the coatings for additional processing by a plasma jet has been calculated by computer simulation. It would be desirable to observe the structures formed in different layers of the coating developed under this temperature field. However, the plasma spray coated samples could not be properly cut due to high brittleness of the samples. After additional processing by a plasma 

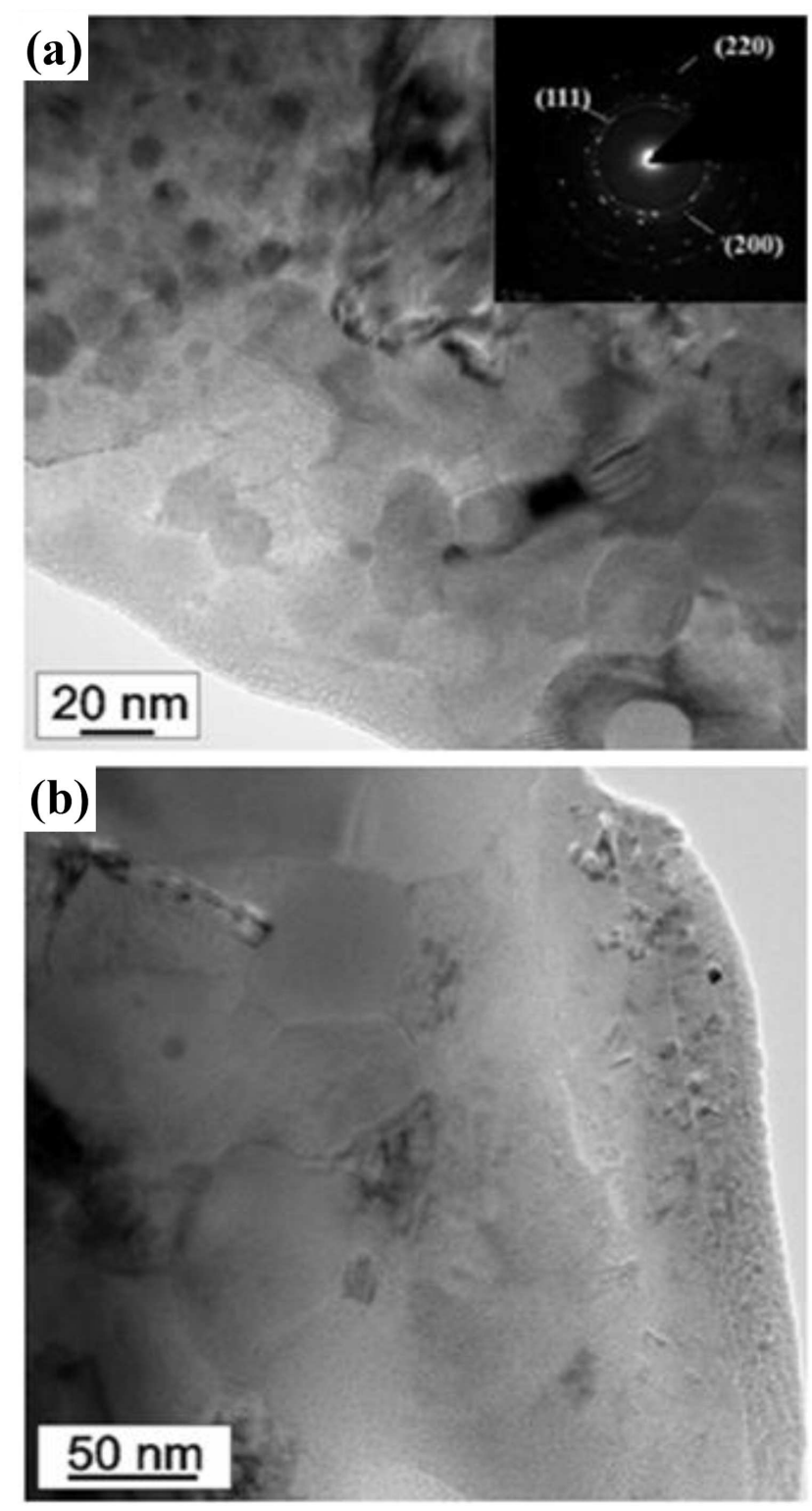

Fig. 1. TEM images of the PG-19N-01 alloy powder coating: (a) a nanograin polycrystalline structure, (b) the area with lamellas of intermetallic $\mathrm{CrNi}_{3}$.

jet, the coatings became more homogeneous and their surfaces were melted. This provided the opportunity of of preparing samples suitable for a TEM study using the cross-section method. However, it is preferable to use the same method of TEM specimen preparation for coatings before and after additional plasma jet treatment in order to reliably compare the results of the TEM analysis. Each stage of TEM specimen preparation introduces damage to the structure under study: surface damage, deforming stresses or overheating, etc. When choosing the same method of TEM specimen preparation, it is expected the same type of damages are induced in all the samples.

It can be seen in Fig. 2, that very good quality TEM samples can be obtained after additional plasma processing. This is due to the uniform thinning across the sample
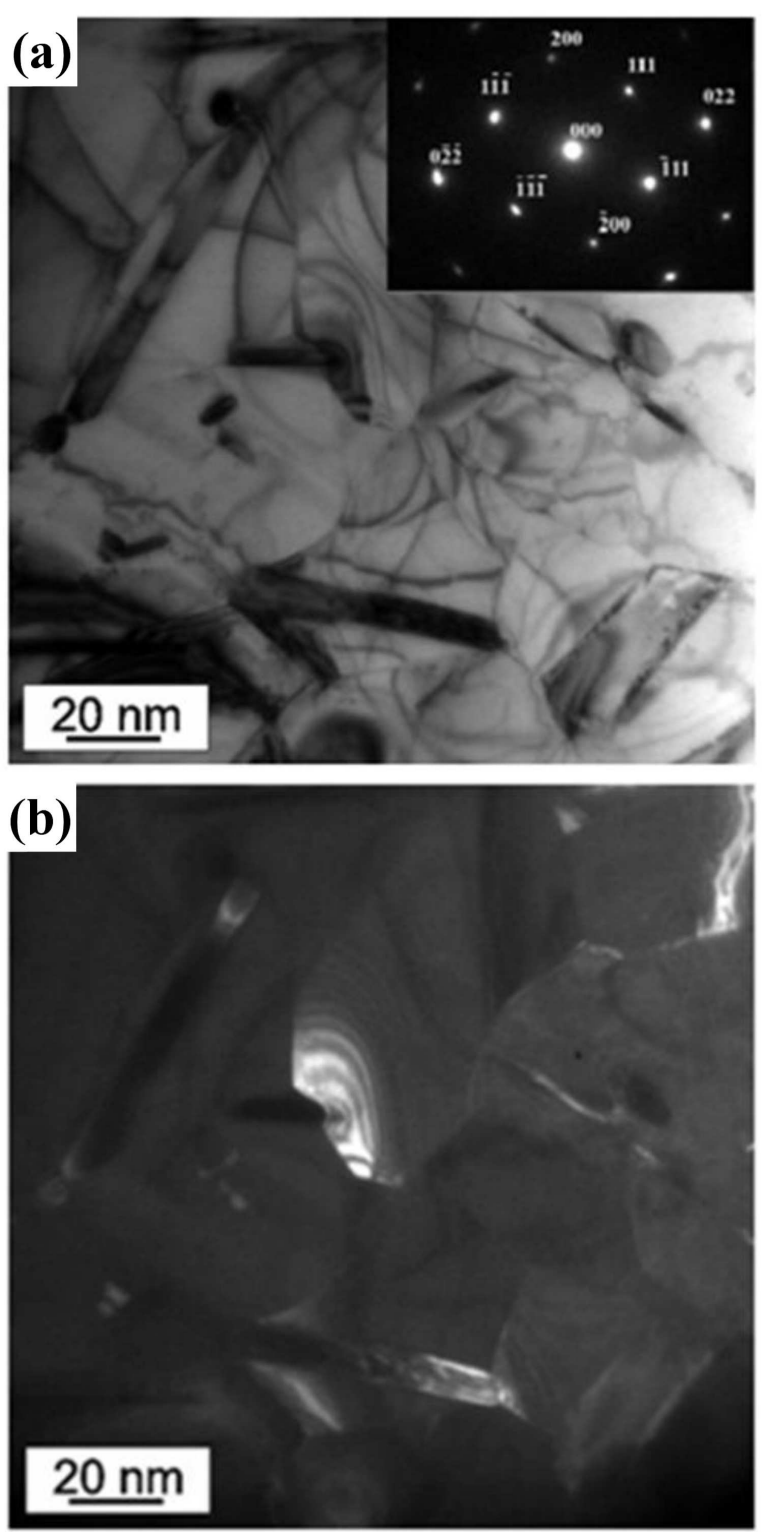

Fig. 2. TEM images of the $\mathrm{CrNi}_{3}$ phase lamellae in the PG-19N-01 powder coating after additional microplasma treatment (a) bright field, (b) dark field shot in point reflex (111).

surface as a result of improved homogeneity of the coating provided by additional plasma treatment. The process has resulted in large electron transparent regions to become available for TEM observation. In the case of specimens of coatings before additional plasma processing, such regions have been located near the through-hole of the foil and had a shorter extension (Fig. 1). Presumably, the use of FIB (focused ion beam) for specimen preparation $[15,18]$ in this case could have been very useful, but this method was not available in this study. We believe that the TEM specimen preparation used here gave satisfactory results and allowed us to use simpler specimen preparation equipment. Using the methods described above, we also succeeded in the investigation of 

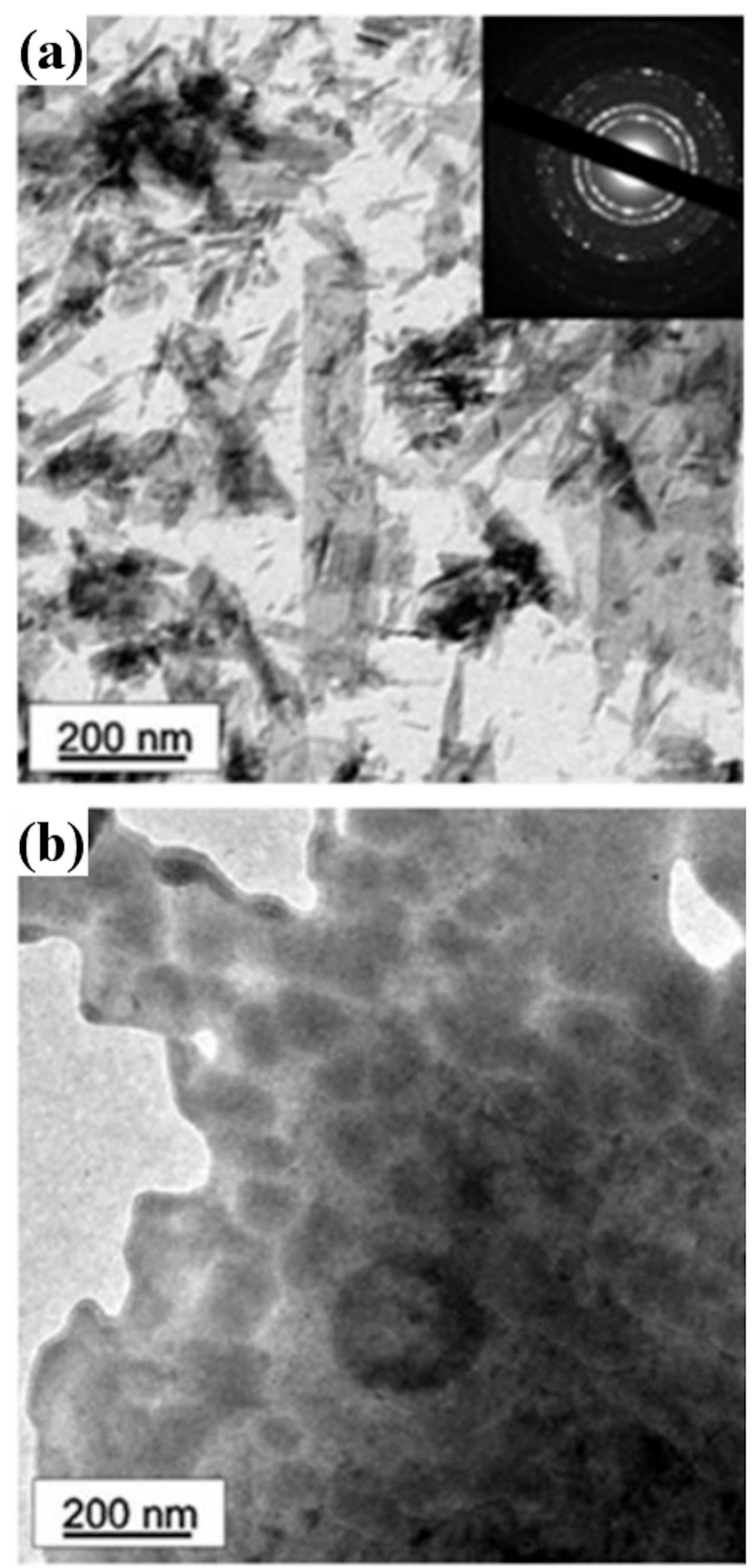

Fig. 3. TEM-images of HA (a) a synthetic HA powder with corresponding microdiffraction pattern, (b) a porous HA plasma spray powder coating.

the HA-powders and coatings obtained from them, which are currently the subject of a TEM study (Fig. 3).

The results of XRD and SEM analysis of HA powder and porosity of HA plasma sprayed coatings are presented in our paper [19]. At the current stage of research, the results of the TEM analysis of HA powder (Fig. 3a) and HA plasma spray coatings (Fig. 3b) are in good agreement with the results of XRD. The crystallinity of the HA powder was found to be $99.96 \%$, which meets requirement for HA powder for medical applications as outlined in ISO 13779-:2000 [20]. The purity was $99 \%$, which meets the purity requirement set out in the ASTM standard [21]. The structure-phase composition in the HA coating was established by XRD as follows: $93 \%$ by weight of the crystalline phase, $5 \%$ by weight of $\beta$-tricalcium phosphate $(\beta$-TCP) phase and 2 $\%$ by weight of the amorphous phase. Areas of the amorphous HA have been found on the X-ray diffraction patterns between 28.9 and $34.2^{\circ} 2 \theta$. The peaks in the X-ray diffraction patterns match the standard diffraction pattern for HA, which provides evidence that the analysed coating is in the HA zone. All the diffraction patterns in the range of $37.3^{\circ} 2 \theta$ (the region for $\mathrm{CaO}$ ) were thoroughly investigated, but even weak peaks of Calcium oxide $(\mathrm{CaO})$ were not found. So, the coating consists of $95 \%$ HA phase. This confirms that the purity meets the requirements of ISO 13779-2:2000 [20]; no harmful Ńr̂̂̀ compound is formed through the plasma spraying coating of HA powder. Thus, the mode of microplasma spraying specified in Table 1 for HA powder provides the required structure-phase composition in the HA coating.

\section{Conclusion}

The methods of specimen preparation thick powder plasma sprayed protective and biocompatible coatings for the TEM investigation have been established. The focus of the study has been on the $\mathrm{Ni}-\mathrm{Cr}$ based alloys powders and hydroxyapatite powders plasma sprayed coating. The use of TEM methods allowed confirming the hypothesis of certain structural-phase transformations in plasma powder coatings under the influence of additional plasma treatment. It was established by TEM and XRD that the coatings have the desired structure-phase composition. The structure of the Ni-Cr-based coating is a nanograined matrix with lamellas of the strengthening nano-sized $\mathrm{CrNi}_{3}$ phase. The volume fraction of this phase increases with additional plasma treatment of the coating according to specific modes. It was established that the mode of microplasma spraying specified in Table 1 for HA powder provides the required structure-phase composition in the HA coating: $93 \%$ by weight of the crystalline phase, $5 \%$ by weight of $\beta$-tricalcium phosphate $(\beta$-TCP) phase and $2 \%$ by weight of the amorphous phase. This composition meets the requirements of International Standard for Coatings of Hydroxyapatite for Implants for Surgery. The investigation of a number of coatings obtained by the methods of microplasma spraying powders on metal substrates showed the advantages and challenges of application of TEM method for analyzing the structure of thick plasma spray powder coatings. These results are of significance and use for a wide range of researchers who develop and implement the plasma spray technologies.

\section{Acknowledgments}

The study has been conducted with the financial support of the Science Committee of RK MES in the framework of the target financing program for the 2017-2019 within the subprogram 0006/PTF-17 "Production of titanium products for further use in medicine". 


\section{References}

[1] R.C. Tucker, in: Thermal Spray Technology, Ed. R.C. Tucker, Vol. 5A, ASM Handbook, 2013, p. 76 .

[2] A.S. Kalinichenko, O.G. Devoino, V.V. Meshkova, Science \&6 Technique 15, 365 (2016).

[3] R.B. Heimann, Surf. Coat. Tech. 201, 2012 (2006).

[4] J.-C. Hsiung. H.-K. Kung, H.-S. Chen, Kuan-Yu Chang, Life Science J. 9, 457 (2012).

[5] J. Buckman, Sh.A. Bankole, S. Zihms, H. Lewis, G. Couples, P. Corbett, Geosciences 7, 1 (2017).

[6] Ch. Chilev, Ya. Stoycheva, M. Dicko, F. Lamari, P. Langlois, I. Pentchev, Int. J. Science, Tech. Society 5, 131 (2017).

[7] P.S. Prevéy, J. Therm. Spray Tech. 9, 369 (2000).

[8] N. Pistofidisa, G. Vourliasb, D. Chaliampaliasc, G. Stergioudisd, E.K. Polychroniadise, Solid State Phenomena 163, 93 (2010).

[9] R. Xina, Ya. Lenga, Ni. Wangb, J. Crystal Growth 289, 339 (2006)

[10] J.M. Zuo, J. Spence, Advanced transmission electron microscopy: Imaging and diffraction in nanoscience, Springer, New York 2016.

[11] K. Balani, A. Agarwal, S. Seal, J. Karthikeyan, Scripta Mater. 53, 845 (2005).

[12] D. Alontseva, E. Ghassemieh, J. Phys. Conf. Series 644, 012009 (2015).
[13] D. Alontseva, E. Ghassemieh, A. Russakova, A. Dzhes, N. Prokhorenkova, J. Phys. Conf. Series 902, 012023 (2017)

[14] D. Alontseva, E. Ghassemieh, A. Russakova, A. Krasavin, N. Prokhorenkova, Acta Phys. Pol. A 134, 374 (2018).

[15] J. Li, Advanced Techniques in TEM Specimen Preparation, in: The Transmission Electron Microscope Ed. Kh. Maaz, In Tech., Shanghai 2012, p. 180.

[16] K. Yushenko, Yu. Borisov, S. Voynarovych, I. Fomakin, Plasmatron for spraying of coatings, Patent No: PCT/UA2003/000014, 2004.

[17] GOST 9722-97 Nickel powder, Technical conditions, Russian Standard (2018)

[18] J. Ayache, L. Beaunier, J. Boumendil, G. Ehret, D. Laub, Sample Preparation Handbook for Transmission Electron Microscopy: Techniques, Springer, Berlin 2010.

[19] D.L. Alontseva, M.B. Abilev, A.M. Zhilkashinova, S.G. Voinarovych, O.N. Kyslytsia, E. Ghassemieh, A. Russakova, L. Łatka, Adv. Mater. Sci. 18, 79 (2018).

[20] Implants for Surgery - Hydroxyapatite. Part 2: Coatings of Hydroxyapatite. International Organization for Standards. BS ISO 13779-2:2000, 2000.

[21] Standard Specification for Composition of Ceramic Hydroxyapatite for Surgical Implants, ASTM F118503, ASTM International (2003). 